\title{
Pharmacy profession in India: Current scenario and Recommendations
}

\author{
Akram Ahmad $^{* a}$, Suleman Atique ${ }^{\mathrm{b}}$, Rajesh Balkrishnan ${ }^{\mathrm{c}}$ and Isha Patelc \\ aDepartment of Clinical Pharmacy, Faculty of Pharmaceutical Sciences, UCSI University, No. 1 Jalan Menara Gading,UCSI Heights, \\ Cheras-56000, Kuala Lumpur, Malaysia \\ ${ }^{b}$ Graduate Institute of Bio-medical Informatics, Taipei Medical University, 250-Wuxing Street, Xinyi District, Taipei 11031,Taiwan \\ 'Department of Clinical, Social and Administrative Sciences, College of Pharmacy, University of Michigan at Ann Arbor, 428 Church \\ Street, Ann Arbor, MI 4810 9-1065, USA
}

\begin{abstract}
The Profession of Pharmacy is an integral part of the healthcare system worldwide. Pharmacies with well-organized practice can go a long way to ensure quality health care for the patient. In the past, pharmacists were responsible for dispensing medications only. Slowly, the traditional role of pharmacists is expanding and now pharmacists are playing a role as a vital team member in the direct care of patients, especially the new generation pharmacists who have Pharm. Ds. Pharmacists play a major role in providing healthcare services by means of community pharmacy services in rural areas where physicians are not available or where physician services are too costly for meeting the healthcare necessities. Many reforms are yet needed to improve job satisfaction among Indian pharmacists such as higher salaries, more job opportunities in government offices, recognition of pharmacists as health care professionals and changes in the Pharm. D and pharmacy curriculum. This report looks at the current issues with the pharmacy profession in India and provides possible recommendations to improve job satisfaction among India pharmacists.
\end{abstract}

Keywords: Pharmacy, satisfaction, India, recommendations

\section{INTRODUCTION}

Pharmacists comprise the third largest healthcare professionals in the world and pharmacy profession has been evolving steadily over the last decade in India. ${ }^{1}$ Today, pharmacists have expanded their role from dispensing to pharmaceutical care by maximizing the benefits of medications and theirsafety. ${ }^{2}$ With the increase in work related activities, it has directly or indirectly influenced the quality of work delivery and job satisfaction in pharmacists. Job satisfaction is defined as a reaction of workers with respect to their roles in the organization that employs them. ${ }^{3}$ It is the degree of favourableness with which employees view their work and is an important contributing factor towards a person's motivation and productivity. ${ }^{4}$ It can determine whether an employee will remain in a position or seek work elsewhere. Furthermore, job satisfaction can influence the quality of work produced. ${ }^{5}$ Lower level of job satisfaction is directly associated with lower life satisfaction and has an effect on an individual's life. ${ }^{6}$ Job satisfaction affects the lives of all workers, including health workers. Both job satisfaction and motivation play an important role in job retention and increased productivity of health workers which in turn improves health system performance. ${ }^{7,8}$ Difficulty in retaining clinical staff in low and middleincome countries makes the already inadequate health care system more fragile. Thus, pharmacists' satisfaction with their work affects not only employees and employers, but also patients who receive the pharmacists' services. A k ram et al. conducted a
DOI: 10.5530/ijper.48.3.3

Address for correspondence: Dr. Akram Ahmad Pharm. D, B.Pharm, D.Pharm

Lecturer, Department of Clinical Pharmacy, Faculty of Pharmaceutical Sciences, UCSI University, No. 1 Jalan Menara Gading, UCSI Heights, Cheras 56000, Kuala Lumpur, Malaysia Mobile: +60-1112285842 E-mail: akram@ucsiuniversity.edu.my

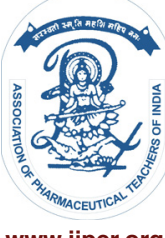

www.ijper.org 
pilot study about job satisfaction among pharmacists in their practice settings. The study constituted a nationally representative sample and showed poor job satisfaction among Indian pharmacists. Pharmacists stated that they didn't like their jobs better than the "average worker.",10

In hospital as well as community pharmacy settings, counselling patients is one of the key roles that pharmacists offer in developed states such as Maharashtra, Tamil Nadu, Kerala and Karnataka. Even today in North India, pharmacists are considered as 'mere drug dealers'. Many states have failed to implement Drugs and Cosmetics Act 1940 and chemist shops in these states run without full time pharmacists. A study conducted in the community pharmacy setup in urban area of North India (New Delhi) showed that $71 \%$ patients got benefit from community pharmacists but pharmacists predominantly have a commercial role, aimed at making profits. ${ }^{11}$ The conditions are too bad in rural areas in India, especially in infrastructural under developed states (Uttar Pradesh, Bihar, Rajasthan, and Madhya Pradesh because most of the pharmacies run without pharmacists. In these states, pharmacy owners have only high school diploma or are illiterate and end up hiring a pharmacist on paper to procure pharmacy license in exchange of an annual payment of $\$ 129$ - $\$ 194$. Furthermore, the general public also regards community pharmacists working in medical stores as a first choice to seek medical counsel for minor ailments but unfortunately pharmacists are not available at all times due to higher workload, increased volume of prescriptions and the number of interactions with patients. ${ }^{12}$ In India, in the community pharmacies, pharmacists just dispense medications and do not counsel patients about taking prescriptions and OTC products. Developed nations have clearly established the role of community pharmacists by providing them with knowledge and techniques to counsel patients, provide information about medicines and disease conditions or advice about life style modifications, drug administration, dosage, side effects, storage of drugs, and drugdrug and drug-food interactions. ${ }^{13}$ Many developed nations such as Australia, United Kingdom, and United States have also given prescription rights to pharmacists and nurses to reduce burden on physicians and improve quality of care. ${ }^{14}$ However, in India, compared to the western world, the role of the community pharmacist is limited.

Since the last decade, pharmacy profession in India is evolving due to industrialization and increase in patient needs, leading to an increase in the demand of pharmacists. According to the Pharmacy Council of India (PCI), there are 6,57,230 registered pharmacists practicing since January 2012.9 In lieu of this large number, there is a need for reforming the structure and policies of governing bodies like Pharmacy Council of India (PCI) and All India Council for Technical Education (AICTE) and several associations such as Indian Pharmaceutical Association (IPA), Indian Pharmacy Graduates Association (IPGA), Indian Hospital Pharmacists' Association (IHPA) and Association of Pharmaceutical Teachers of India (APTI) to improve job satisfaction among pharmacists. ${ }^{15,16}$ We propose the following recommendations:

\section{Salaries and job opportunities}

Pay scale should be reasonable and competitive for every specialty of the pharmaceutical field to prevent exploitation since the salaries are considerably less in private hospitals, community pharmacies and the industry. ${ }^{10}$ Pharmacy governing bodies like the Pharmacy Council of India (PCI) and the All India Council for Technical Education (AICTE) should stop issuing licenses for opening new pharmacy institutions due to the current lack of vacancies for already passed out graduates and due to the prevailing concern about the quality of education provided in pharmacy institutions. More job opportunities should be created for passed out graduates in the government and private sector. All states should implement the Drug and Cosmetics Act, 1945 like Maharashtra so that more pharmacists can procure jobs in community pharmacies with good pay scale. In addition, PCI should maintain electronic records of registration details and contacts of pharmacists working across the nation (including academia) as well as the available job vacancies.

\section{Recognition of pharmacists}

Pharmacists can play an important role in providing quality health care by working along with physicians. A team of 5-6 pharmacists should be appointed in PHCs (Primary Health Centres) at panchanyat level and in CHCs (Community Health Centres) at the block/tehsil level. There should be presence of a pharmacy officer working under a medical officer at the $\mathrm{CHC}$ and $\mathrm{PHC}$ level and similarly in each district, there should be the presence of a chief pharmacy officer (CPO) working under a chief medical officer (CMO). Drug inspectors must be appointed at tehsil level in addition to their appointment at the district or regional level for proper regulation. Pharmacy teachers and pharmacists working in hospitals and industries should be given due recognition, especially in the pharmaceutical industry where many art and science graduates occupy many of the pharmacy based jobs. The Department of Pharmaceuticals (DoP) should be recognized as part of the Ministry of Health and not as part of the Ministry of Chemicals \& Fertilizers, both at the central level and the state level since pharmaceutical products' (life saving 
medicine, surgical products, cosmetics) procurement, formulation, manufacturing, quality analyses, labelling and dispensing undergo a very different process, unlike chemicals and fertilizers.

\section{Working practice}

Pharmacists should be majorly involved in and employed for manufacturing pharmaceuticals due to their expertise in the field. Presently, a number of art and science graduates with no basic knowledge about pharmaceuticals work in pharmaceutical industries. ${ }^{910}$ Some measures to be taken by PCI to improve pharmacy practice should be prohibiting physicians from storing medicines in absence of a pharmacist, compulsory mention of the name of the pharmacist who dispensed the prescription along with the name of the physician who issued the prescription, prohibiting pharmacists from sale of prescription medications over the counter, renaming "medical stores" as "pharmacies", making hiring of pharmacists mandatory in addition to procuring a pharmacist licensure in pharmacies run by non-pharmacists and trying to limit working hours for practicing pharmacists to a maximum of 8 hours per day.

\section{EDUCATION}

The practice of earning a diploma in pharmacy as the minimum requirement to be a registered pharmacist should be discontinued and all the students should be compulsorily made to earn a 4 year degree course in pharmacy since India is one of the few countries that allows candidates earning both, a 2 year diploma as well as a 4 year degree program in pharmacy respectively, to practice as independent pharmacists. This practice is unlike the developed countries, where candidates holding a diploma in pharmacy do not hold as many powers and responsibilities as candidates holding a 4 year pharmacy degree. Candidates with a diploma in pharmacy might not have as much knowledge as the candidates with a 4 year pharmacy degree. Also, the diploma in pharmacy curriculum is not updated on a regular basis which stresses the importance of procuring the four year bachelors of pharmacy (B.Pharm) degree. B.Pharm must be the preferred qualification for pharmacists instead of D.Pharm. Pharmacy Council of India (PCI) states that B.Pharm graduates should register under state pharmacy council and become registered pharmacists after being issued a certificate from the State Pharmacy Council. However, in spite of being registered as pharmacists, they are not eligible for pharmacist vacancies in health care centres.

Certain graduate institutions such as National Institute of Pharmaceutical Education and Research (NIPER) who are a separate organization for pharmaceutical sciences allow non-pharmacy students from other fields such as alternative medicine, veterinary sciences, dentistry and medicine to apply for master's and doctoral positions in different specializations of pharmacy. ${ }^{15}$ These students do not have a bachelor's degree in pharmacy. Pharmacy graduates are not permitted to pursue post- graduation in any of the above fields without completing a bachelor in the same. Even though in other developed countries, students have a freedom to pursue post graduation in the field of their choice, a similar practice is not prevalent in India. Hence, an inconsistency can be seen in the implementation of educational policies and the opportunities to procure advanced degree programs in the pharmacy field. Pharmaceutical science is a professional subject like medicine, engineering, agriculture and veterinary sciences but it is not included in the curriculum of civil services examination (Union Public Service Commission (UPSC), State Public Service Commission (SPSC). ${ }^{15,16}$ Pharmaceutical sciences must be included in civil service curriculum so that pharmacy graduates can also compete in securing governmental positions at the higher level.

\section{CONCLUSION}

The pharmacist with PharmD or M.Pharm can serve as a vital source of drug information or polypharmacy for the physician, nurses, other healthcare professionals and patients; perhaps the only professional who can help in the reduction of drug-related problems and drug interactions, providing cost effective therapy and determining drug-related effects on blood biochemistry. ${ }^{13}$ For example, in a case where there is concurrent administration of agonists or antagonists, the pharmacist can play a vital role by providing information about the appropriate dosage to attain the maximum possible therapeutic effect of the co-administered medicines. Furthermore in treating geriatric and pediatric patients with polypharmacy issues, the pharmacist can play a major role in therapy compliance and improving quality of life through effective counselling sessions. Also, among patients with chronic ailments such as diabetes mellitus, bronchial asthma, hypertension, hyper lipidemia, osteoporosis, psychotic disorders, and other infectious diseases, the pharmacist can improve therapy outcomes and physical well-being via medication therapy management. ${ }^{2,13}$ Many studies have demonstrated that intrinsic and extrinsic factors are valid and are important variables to consider when evaluating job satisfaction among pharmacists. Intrinsic factors such as challenge, performance, and autonomy; and extrinsic factors such asrewards, salary, benefits, job atmosphere, advancement, and management concerns are significant and major predictors of job satisfaction. Further 
study of these variables by a multidisciplinary team can improve levels of job satisfaction among Indian pharmacists. The government policy makers should implement policies based on based on the intrinsic and extrinsic factors to raise employee satisfaction in the workplace. Pharmacy and medical (drug related) authorities should also at the state and local level, undertake initiatives to enhance the role of pharmacists in both community settings and hospitals to improve the therapeutic outcomes for patients, generate and improve pharmacist job satisfaction, and improve health and medication related awareness among people.

\section{ACKNOWLEDGEMENT}

None Declared

\section{CONFLICTS OF INTEREST}

None Declared

\section{REFERENCES}

1. Nicola H. The global pharmacy work force: Systematic review of the literature. Human resource for health. 2009; 7(48): 1478-4491.

2. Kumar AY, Kumar RV, Ahmad A, Mohanta GP, Manna PK. Pharmacists interventions and pharmaceutical care in an indian teaching hospital: A prospective study. Int J Adv Res Pharm Bio. 2012; 1: 386-96.

3. Aziri B. Job Satisfaction: A Literature Review. Management Research and Practice. 2011; 3(4): 77-86.

4. Armstrong M. A Hand book of Human resource Management Practice. Kogan Page Publishing, London, Tenth Edition; 2006.
5. McHugh PP. Pharmacists' attitudes regarding quality of work life. J Am Pharm Assoc. 1999; 39: 667-76.

6. Koustelios A. Personal characteristics and job satisfaction of Greek teachers. International journal of educational management. 2001; 15(7): 354-8.

7. David H. Job satisfaction and motivation of health workers in public and private sectors; cross sectional analysis from two Indian states. Human resource for health. 2010; 8(27): 1478-4491.

8. Mischa W. Motivation and retention of health workers in developing countries; a systematic review. Biomed central Health service research. 2008; 8(247): 1472-6963.

9. Jain V, Priya R, Shubhi R, Preeti S, Ashuthosh P, Yashumati R. Evaluation of job satisfaction \& social identity of rural Indian pharmacists. Ind J Pharm Prac. 2013; 6(1): 47-58.

10. Akram Ahmad, Isha Patel. Job satisfaction among Indian pharmacists, Journal of Pharmacy and Bioallied Sciences. 2013; 5(4): 326.

11. Sharma H, Jindal D, Aqil M, Alam M. S, Karim S, Kapur P. A survey for assessment of the role of pharmacist in community pharmacy services. J Pharm Bioall Sci. 2009; 1(1): 23-6.

12. Schommer J. Pharmacist workload and time management. Drug TopicsVoice of the Pharmacist (part of the CE program). 2001. ACPE \# 032999-01-003-H04. Available at: http://drugtopics.modernmedicine.com/ drug-topics/news/pharmacist-workload-and-time-management?page=full. Accessed June 9, 2014.

13. Abdul Haseeb, Mahmoud E. Elrggal, Recommendations for the role of the pharmacist in Saudi Arabia. Archives of Pharmacy Practice. 2013; 4 (3): 138.

14. Abhishek Sharma, Elissa Ladd, Unnikrishnan M K. Healthcare Inequity and Physician Scarcity Empowering Non-Physician Healthcare. Economic \& Political Weekly (EPW). 2013; 48(13): 113-7.

15. UDF demands creation of Indian Pharma Service to enhance prospects of pharmacists, Pharmabiz, Wednesday, May 09, 2012, http://pharmabiz.com/ NewsDetails. aspx ?aid=68889\&sid=1, Accessed Dec 2, 2013.

16. Deepak Singh, Dharam Veer Singh. Why the Pharmacy Education and Profession in India demands still more sacrifice, hard work and in resultant, we are not getting, http://www.pharmatutor.org/forum/latest-updates/ pharmacy-education-and-profession-in-india-demands-still-more-sacrificehardwork, Accessed Dec 25, 2013. 